\title{
Reparación primaria de los flexores en la zona II. Actualización y técnica quirúrgica
}

\author{
Violeta D. Levy \\ Sección Cirugía de Mano y Miembro Superior, Servicio de Ortopedia y Traumatología, Hospital Español de Buenos Aires, Argentina
}

\begin{abstract}
RESUMEN
La reparación primaria de los tendones flexores en la zona II ha sido un desafío desde el surgimiento de la cirugía de la mano como especialidad luego de la Segunda Guerra Mundial. Desde Bunnell hasta hoy, la forma de operar y rehabilitar estos tendones ha evolucionado y cambiado considerablemente gracias a estudios anatómicos, biológicos y, sobre todo, mecánicos. Actualmente la técnica quirúrgica se basa en realizar una sutura fuerte y prolija, que no sufra fricción dentro de la vaina y que tolere la carga necesaria para la movilidad activa del dígito sin resistencia. Se han descrito múltiples configuraciones de puntos con diferentes materiales. Operando con anestesia local, la prueba de flexo-extensión activa intraoperatoria revela la resistencia del tipo de sutura elegida y ha cobrado importancia para definir el protocolo de rehabilitación. El tratamiento de los flexores en la zona II es, hasta el momento, un conjunto inseparable de técnica quirúrgica y rehabilitación asociada. La manipulación farmacológica del proceso biológico reparador es el principal campo de investigación actual.
\end{abstract}

Palabras clave: Flexores; reparación primaria; zona II.

\section{Primary Flexor Tendon Repair in Zone II. Update and Surgical Technique}

\section{ABSTRACT}

Primary flexor tendon repair in zone II has been a challenge since the emergence of hand surgery as a specialty after World War II. From Bunnell to today, the way of operating and rehabilitating these tendons has evolved and changed considerably thanks to anatomical, biological and --above all --mechanical studies. Currently, the surgical technique is based on performing a strong and neat suture, which does not suffer friction within the sheath and which tolerates the load necessary for the active motion of the finger without resistance. Multiple suture configurations with different materials have been described. Under local anesthesia, the intraoperative active flexion-extension test reveals the resistance of the type of suture chosen and has gained importance in defining the rehabilitation protocol. Treatment of flexors in zone II is, so far, an inseparable set of surgical technique and a suitable rehabilitation protocol. Biological strategies to enhance the tendon healing process are currently the main field of research.

Keywords: Flexor tendon; primary repair; zone II.

\section{INTRODUCCIÓN}

Las lesiones de tendones no son comunes, tienen una incidencia de 4,8 cada 100.000 habitantes. ${ }^{1}$ Aun así, su reparación es uno de los tópicos más importantes de la Cirugía de la Mano. El objetivo de este artículo es describir y fundamentar la técnica quirúrgica que utilizo para tratar lesiones de los flexores en la zona II, ya que, en los últimos 30 años, han surgido cambios tanto en los tipos de reparaciones como en el tratamiento de la vaina y los protocolos de rehabilitación asociados. Por otro lado, el conocimiento cada vez más amplio de la biología tendinosa ha promovido nuevos campos de investigación para futuros avances que describo brevemente.

\section{INDICACIONES Y CONTRAINDICACIONES}

La reparación primaria de los flexores en la zona II está indicada siempre que sea posible. No se trata de una emergencia, salvo que exista desvascularización del dígito o los dígitos afectados. Es determinante que haya un especialista disponible en la sala de urgencias. Dada la cantidad de detalles técnicos y la disponibilidad de instrumental y materiales específicos necesarios, es preferible, si no hay un especialista, realizar una limpieza, suturar la piel y derivar al paciente para una sutura primaria diferida que tiene indicación hasta 21 días después del trauma con iguales resultados (Figura 1).

Recibido el 20-4-2021. Aceptado luego de la evaluación el 8-5-2021 • Dra. VIOLETA D. LEVY • vdlevy @gmail.com (ID https://orcid.org/0000-0003-1822-673X Cómo citar este artículo: Levy VD. Reparación primaria de los flexores en la zona II. Actualización y técnica quirúrgica. Rev Asoc Argent Ortop Traumatol 2021;86(5):681-695. https://doi.org/10.15417/issn. 1852-7434.2021.86.5.1356 


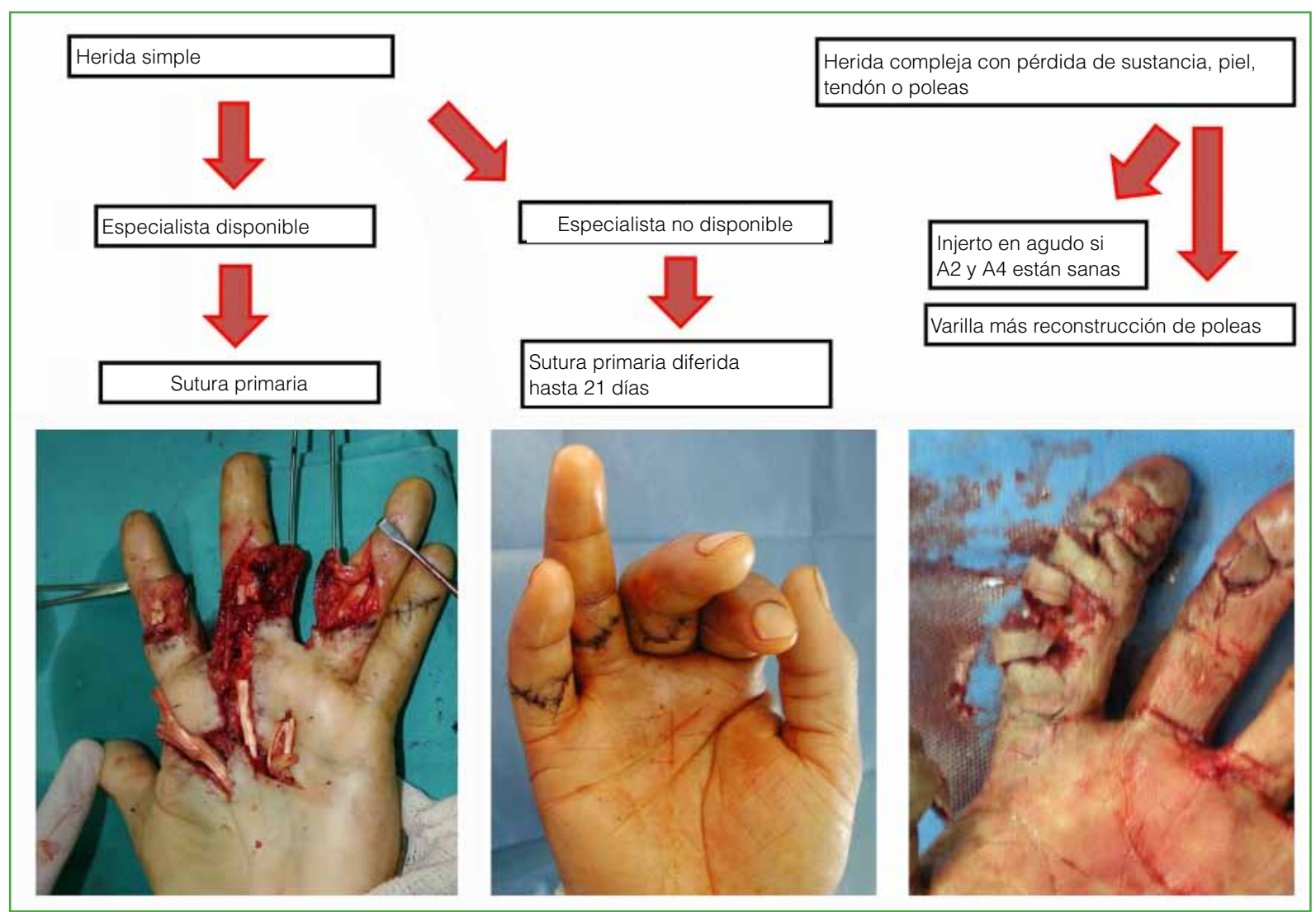

Figura 1. Algoritmo de tratamiento.

Podría describir las heridas como simples (piel, flexores y hasta un paquete vasculonervioso) o complejas (pérdida de sustancia, asociación de lesión grave de piel o ambos paquetes, vaina extendida o fracturas de falanges). Si la herida es compleja, la prioridad es la revascularización acompañada de reparación nerviosa; también, tendrán que llevarse a cabo otros procedimientos, además de las tenorrafias, como estabilizaciones óseas o colgajos de piel, según corresponda. Si la lesión compleja presenta un daño sustancial de la vaina flexora, es preferible colocar una varilla de Silastic, reconstruir poleas y programar un segundo tiempo para injerto a los 3-6 meses (Figura 2). Podría suceder, aunque es poco frecuente, que las poleas más importantes estuvieran sanas y faltara sustancia en los flexores, en cuyo caso se podría colocar un injerto de flexor en la primera cirugía.

La reparación primaria de los flexores en heridas complejas no está contraindicada, pero requiere de estabilizaciones óseas firmes, suturas vasculares y nerviosas sin tensión, y buena cobertura cutánea para ingresar en protocolos de rehabilitación temprana. Si esto no fuera posible, hay que advertir al paciente sobre la posibilidad de futuras intervenciones para eventuales tenólisis o reconstrucciones secundarias.

\section{ANATOMÍA QUIRÚRGICA}

\section{Conceptos básicos}

La zona II de Verdan se extiende desde el pliegue palmar distal hasta casi el pliegue interfalángico distal. Contiene el flexor superficial de los dedos (FDS), el flexor profundo (FDP), la vaina sinovial, el sistema de poleas, las falanges y los paquetes neurovasculares. El FDP que se inserta en la base de la tercera falange y el FDS que se inserta a través de dos bandeletas en la superficie volar de la segunda falange, se cruzan en el quiasma de Camper que comienza en la parte media de la primera falange y finaliza en la parte media de la segunda. ${ }^{2}$ 


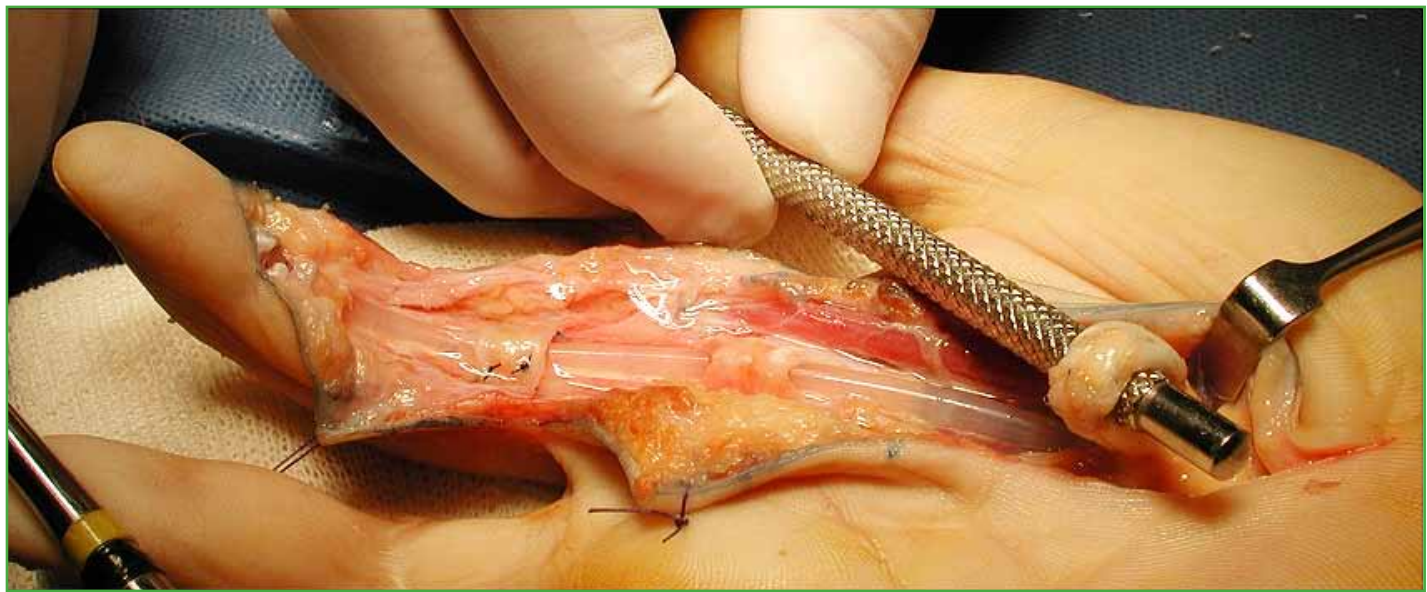

Figura 2. En heridas complejas con destrucción de la vaina: colocación de varilla y reconstrucción de poleas A2 y A4. Asa entre flexor superficial y profundo (Paneva-Holevich).

Las vainas tienen una hoja parietal y otra visceral, y contienen líquido sinovial. Las de los dedos segundo, tercero y cuarto llegan hasta el pliegue palmar distal y terminan en fondos de saco, la del pulgar o radial llega hasta la muñeca. La vaina cubital, también llamada del flexor común, recubre los flexores del quinto dedo y, a nivel del túnel del carpo, engloba también los flexores de los dedos cuarto, tercero y segundo terminando a nivel de la muñeca. ${ }^{3}$ La región palmar de los flexores centrales (zona III) es extrasinovial y está recubierta por un tejido conectivo llamado paratendón. En la zona digital propiamente dicha, se conforma un túnel osteofibroso reforzado por poleas que son engrosamientos de tejido conectivo denso; están distribuidas segmentariamente a lo largo de los dedos y su función es maximizar la eficiencia mecánica de la excursión tendinosa. Existen cinco poleas circulares y tres cruciformes. ${ }^{4,5}$ Las poleas A2 y A4 son las más importantes desde el punto de vista mecánico (Figura 3).

Los tendones flexores se nutren a través de la unión musculotendinosa, la unión osteotendinosa, el paratendón en la porción extrasinovial, las vínculas y por difusión en la porción intrasinovial. Las vínculas son bandas que contienen vasos y van desde la base ósea del túnel digital hacia la cara dorsal de los flexores. Existe una víncula corta y otra larga para cada flexor (Figura 3). ${ }^{6}$

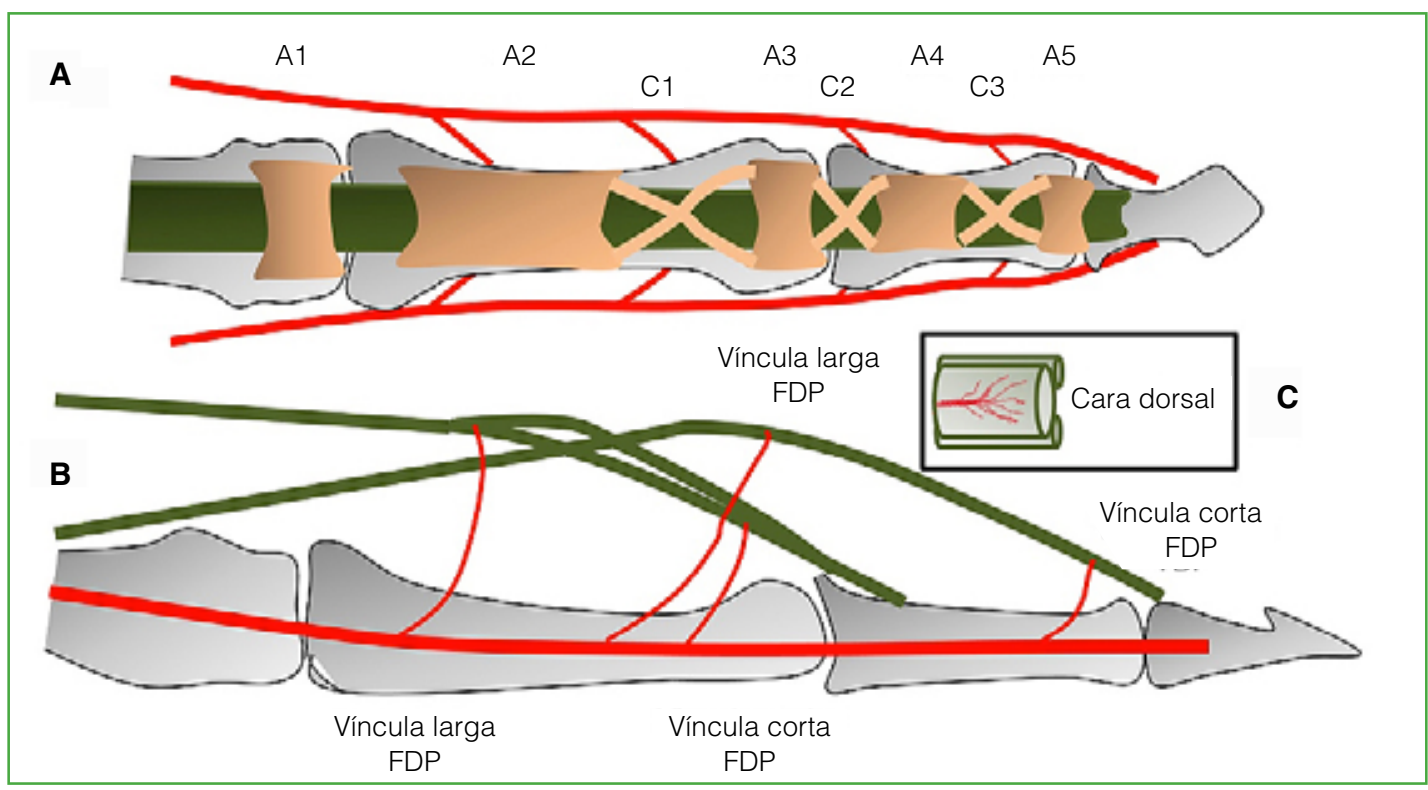

Figura 3. A. Sistema de poleas. B. Vínculas. C. Ingreso de las vínculas por la cara dorsal del flexor. FDS = flexor superficial, FDP = flexor profundo. 


\section{Biología de la reparación tendinosa}

La matriz extracelular es el principal componente del tendón y está formada por colágeno tipo I y proteoglicanos sintetizados por los tenocitos inmersos en dicha matriz. ${ }^{7}$ Existen células indiferenciadas que se encuentran en el epitendón y maduran a medida que quedan atrapadas en la matriz disminuyendo progresivamente su metabolismo. ${ }^{8}$ Las fases de reparación tendinosa son tres: la primera inflamatoria que dura entre uno y cinco días, la proliferativa que dura cuatro semanas y la de remodelación que dura alrededor de cuatro meses. ${ }^{9}$ Son las células indiferenciadas del epitendón las responsables de la fase proliferativa y se dirigen hacia el interior del tendón reparándolo y hacia afuera provocando adherencias. El éxito de la reparación depende de la capacidad de reclutar estas células en el sitio de la lesión. Dicho reclutamiento se ve favorecido por la presencia de citocinas o factores de crecimiento que llegan por los vasos. La manipulación farmacológica de este proceso es motivo de investigación actual.

\section{Biomecánica}

Históricamente las reparaciones en la zona II fracasaban, motivo por el cual Bunnell la denominó "tierra de nadie". ${ }^{10}$ Fue recién a partir de 1960, con los estudios de Verdan, ${ }^{11}$ Kleinert y cols., ${ }^{12}$ y Kessler y Nissim ${ }^{13}$ que comenzaron las reparaciones acompañadas de protocolos de movilización temprana con buenos resultados. Los fundamentos de la reparación flexora fueron bien descritos por Strickland: ${ }^{14}$ suturas fáciles de realizar, prolijas, que no interfieran con la vascularización tendinosa y lo suficientemente fuertes para permitir la movilización temprana. Tang y cols. ${ }^{15}$ describieron tres factores mecánicos que influyen en el resultado de una sutura primaria en la zona II: la fricción, la carga y la movilidad. La fricción es la resistencia al deslizamiento entre el tendón reparado y su vaina, es conveniente que sea mínima (el tendón no debe trabarse al deslizarse) y si, para evitarla, hay que abrir poleas es preferible hacerlo. Clásicamente siempre se intentó mantener la vaina cerrada para conservar una barrera que evite adherencias, restablecer la nutrición sinovial, conservar una guía para la remodelación tendinosa e impedir la cuerda de arco. Sin embargo, los estudios de Tang demuestran que evitar la fricción es más importante. Si el resto de la vaina está sana, se puede dejar abierto hasta dos tercios de A2 y toda A4 sin que se produzca cuerda de arco. También se puede aliviar la fricción a nivel de A2 resecando una de las bandeletas de inserción del flexor superficial. ${ }^{16}$ La carga es la fuerza mínima necesaria para mover las articulaciones del dedo y vencer la fricción (work of flexion) que, según estudios experimentales, es de 35 N. Por lo tanto, el tipo de sutura elegida debe soportar alrededor de $40 \mathrm{~N}$ para realizar el "work of flexion" desde el inicio. La movilidad es indispensable, ya que evita las adherencias y ayuda a recuperar la fuerza ténsil.

El resultado de la sutura realizada debería ser probado con el paciente despierto para observar si hay fricción o separación de los cabos (gapping) durante la flexo-extensión activa en la mesa de operaciones (digital extensionflexion test, DEFT). ${ }^{17} \mathrm{El}$ método descrito por Lalonde de anestesia local con epinefrina y sin manguito hemostático (Wide Awake Local Anesthesia no Tourniquet, WALANT) es el ideal para llevar a cabo esta prueba. ${ }^{18}$

\section{Tipos y materiales de suturas}

Durante los primeros 10 días posteriores a la tenorrafia, toda la resistencia de la reparación depende exclusivamente del material y el tipo de sutura; por esta razón, han sido exhaustivamente estudiados. El acuerdo general es que hay que realizar un punto central y un surget periférico, ambos pueden tener diferentes configuraciones. El punto central puede ser convencional ( 2 hebras pasantes) o multihebra (4, $6 \mathrm{u} 8$ hebras pasantes) (Figura 4), los amarres (grasping) pueden ser no trabados o trabados ("lockeados") (Figura 5). La sutura periférica o surget puede ser continua simple (simple running) o trabada. En cuanto a los materiales, la gran mayoría utiliza nailon o Prolene ${ }^{\circledR} 3$ o 4-0. Durante la última década, se comenzó a usar FiberWire ${ }^{\circledR}$ 4-0 que es un polietileno multifilamento más resistente, pero que se desliza con mayor dificultad. ${ }^{19}$ Actualmente se comercializan suturas tanto de nailon como FiberWire ${ }^{\circledR}$ que incluyen hebras dobles (con una sola aguja incorporada) en loop, al utilizarlas, se dejan dos hebras con cada pasada simplificando el procedimiento y evitando manipular demasiado los cabos tendinosos (Figura 4). ${ }^{20}$ Se están probando dispositivos, como el Teno Fix ${ }^{\circledR}$ que es un cable de acero inoxidable con arpones en los extremos, más resistente, pero más rígido y las suturas barbadas que, según algunos artículos, presentarían la misma resistencia que una sutura de cuatro hebras. ${ }^{21,22}$ La principal crítica a estos sistemas, sobre todo al Teno Fix ${ }^{\circledR}$, es que producen cierto abultamiento en el tendón que podría aumentar la fricción. La sutura ideal es la que no provoca fricción (poco abultada) y resiste, al menos, $40 \mathrm{~N}$ de fuerza para poder realizar la movilidad activa temprana. En la Tabla 1, se detallan los factores que ayudan a mejorar su resistencia. 


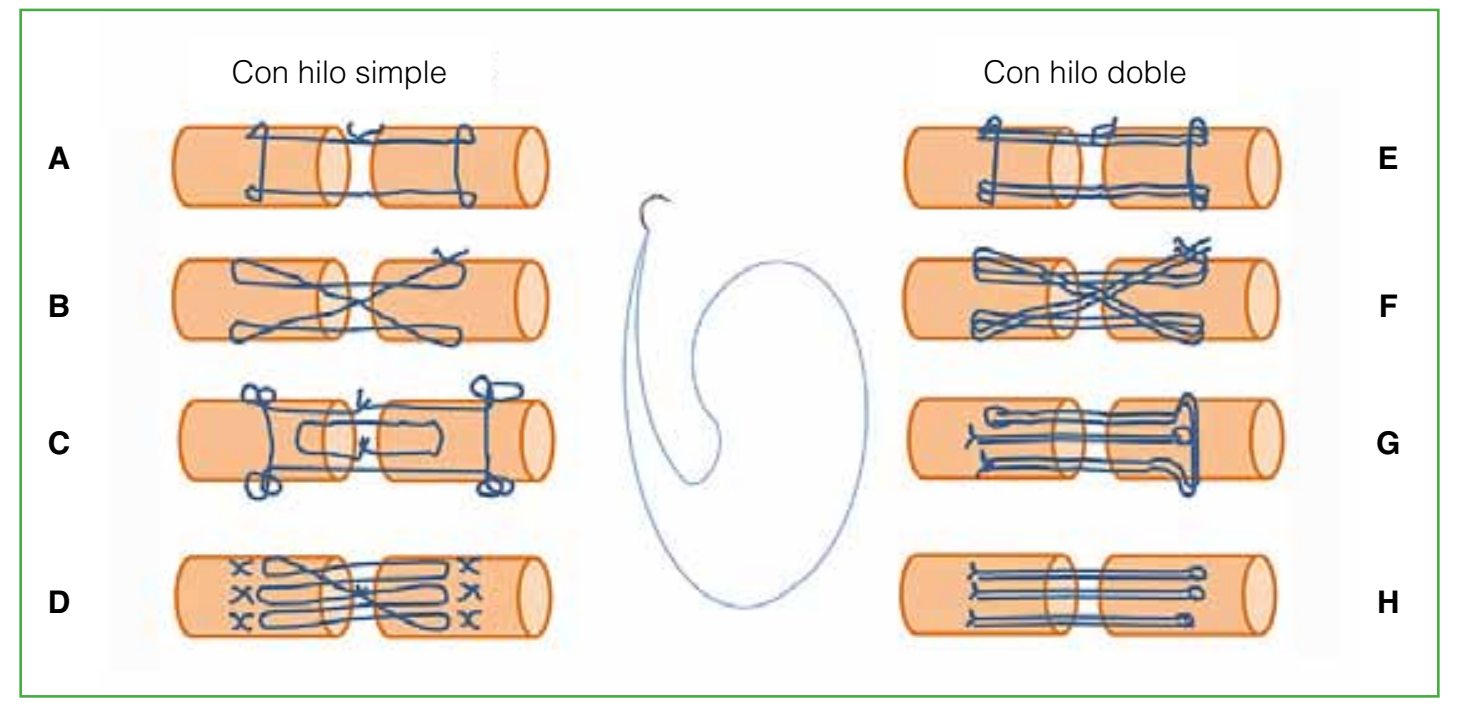

Figura 4. Configuraciones de punto central. Con hilo simple: A. Kessler modificado (2 hebras). B. Adelaide reparación cruzada (4 hebras). C. Strickland (4 hebras). D. Savage (6 hebras). Con hilo doble: E. Kessler modificado (4 hebras). F. Reparación cruzada (8 hebras). G. M Tang (6 hebras). H. Surget triple (6 hebras).

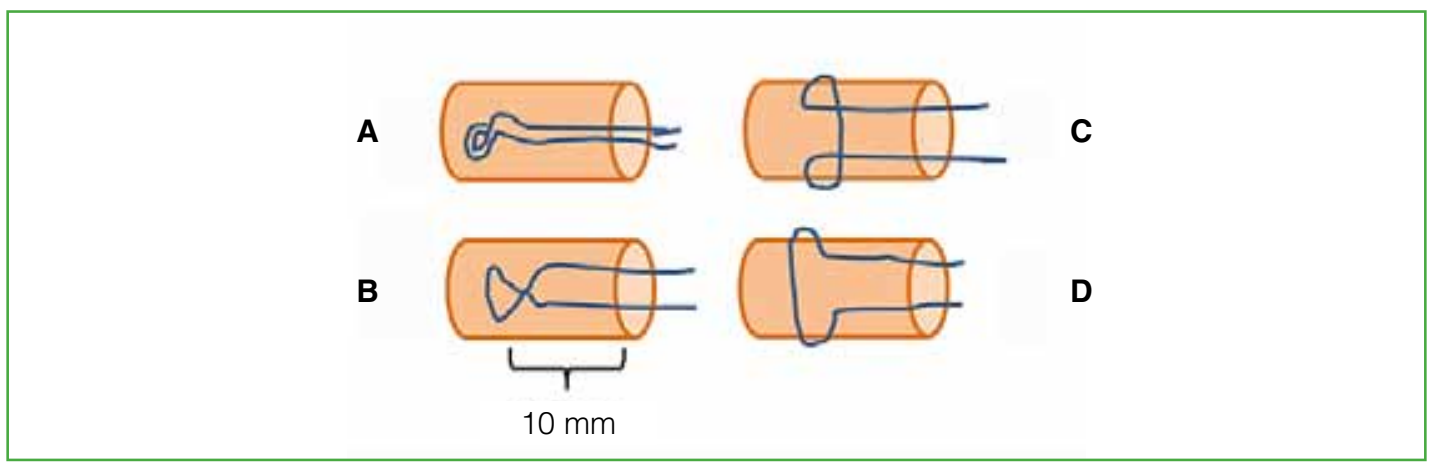

Figura 5. Tipos de amarres. A. Loop. B. Cruzado. C. Pennington. D. No trabado. La distancia óptima entre el amarre y el borde del cabo es de $10 \mathrm{~mm}$.

Tabla 1. Factores que mejoran la resistencia de la sutura

\section{Factores que mejoran la resistencia del punto central}

4 o más hebras pasantes de $1 \mathrm{~cm}$ de largo entre amarre y final del cabo

Por lo menos, 4 amarres trabados

Tensión que acerque los cabos sin abultarlos (acortarlo un 10\%)

Material nailon o Prolene $₫ 3$ o 4-0, FiberWire $\AA$ 4-0
Factores que mejoran la resistencia del surget

De 6 a 8 puntos

Sutura continua trabada

Tomando 1 o $2 \mathrm{~mm}$ de tendón

Material nailon 5 o 6-0 


\section{Posoperatorio y protocolos de rehabilitación}

El tratamiento de los flexores en la zona II es, hasta el momento, un conjunto inseparable de técnica quirúrgica y rehabilitación asociada. La movilidad produce una rápida recuperación de la fuerza ténsil, menores adherencias y mejor excursión tendinosa. Se puede realizar flexión pasiva y extensión activa (Duran, ${ }^{23}$ y Kleinert y cols ${ }^{12}$ ) que produce cierto enrulamiento del tendón dentro de la vaina $;{ }^{24}$ flexión pasiva, extensión activa más flexión activa isométrica al final del movimiento llamado place and hold $\left(\right.$ Silversköld $^{25}$ y Strickland ${ }^{26}$ ), por último, flexión activa no resistida desde el cuarto día adaptando la carga al estadio de la reparación; durante las dos primeras semanas, no es conveniente que la flexión activa sea $>50^{\circ}$ en la articulación interfalángica proximal (Figura 6). ${ }^{27}$ En cualquier caso, al finalizar la operación, debe colocarse una valva dorsal de protección con la muñeca neutra o en leve flexión, articulaciones metacarpofalángicas a $45^{\circ}$ e interfalángicas libres. Cuando se indica flexión pasiva con banda elástica, se puede agregar una barra o polea en la palma para optimizar la excursión del FDP. ${ }^{28}$

Es importante destacar que la elección del protocolo de rehabilitación está determinada por el tipo de sutura realizada y el perfil del paciente. Si la sutura no es confiable (no tiene 4 hebras de, al menos, nailon 3 o $4-0$ con 4 amarres y surget), si no se probó el DEFT o el paciente no cumple las indicaciones responsablemente, es desaconsejable realizar la movilidad activa temprana (Figura 7).

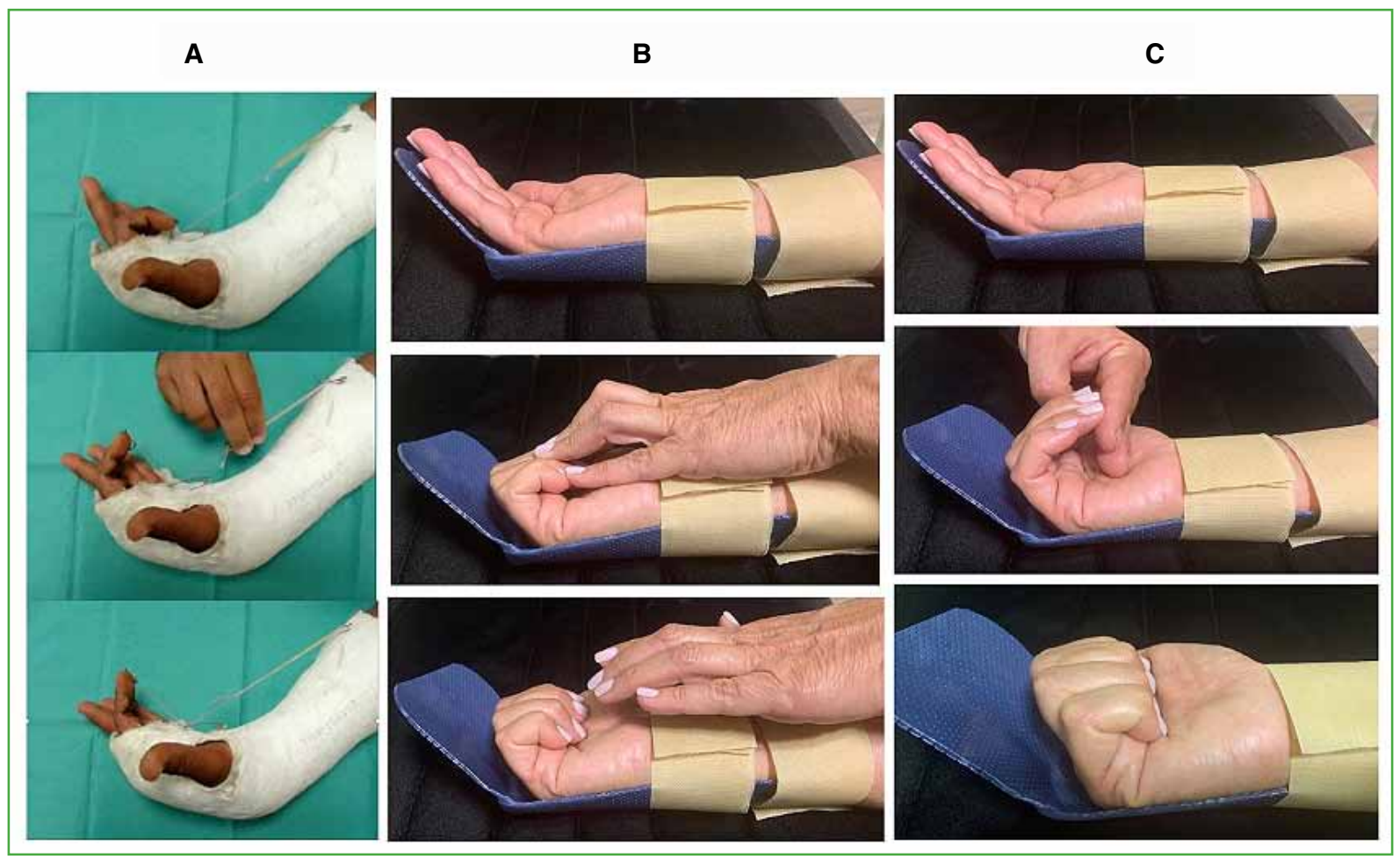

Figura 6. Protocolos de rehabilitación. A. Kleinert: extensión activa, flexión pasiva con banda elástica. B. Strickland: extensión activa, flexión pasiva con la mano sana (Duran) más flexión activa isométrica (place and hold). C. Tang: flexión activa no resistida controlada, los primeros 15 días se colocan 2 dedos de la mano contralateral para evitar la flexión completa. 


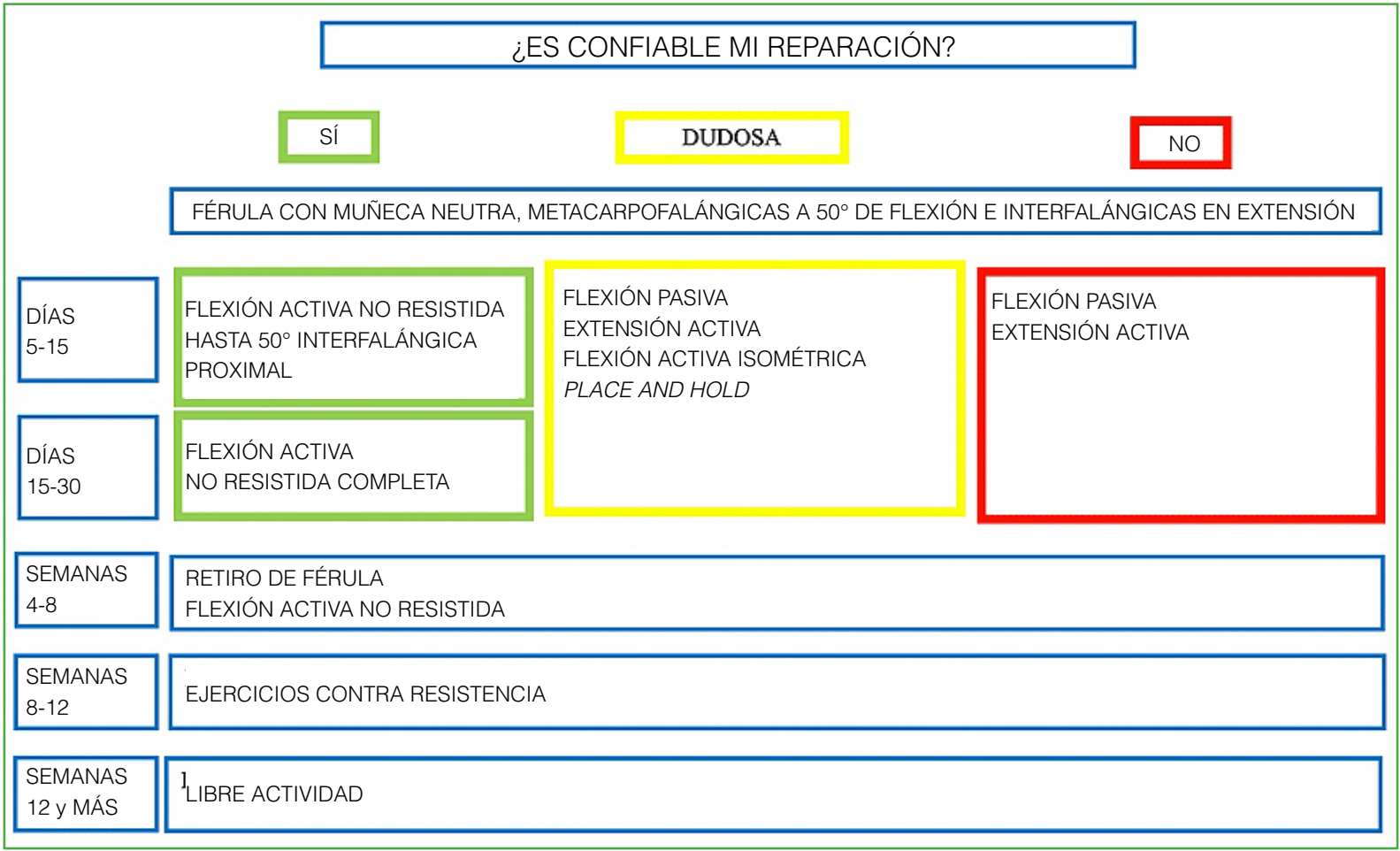

Figura 7. Protocolo de rehabilitación ajustado al tipo de reparación.

\section{TÉCNICA QUIRÚRGICA. MIS PREFERENCIAS}

En los casos de heridas complejas, trabajo con anestesia plexual y manguito hemostático. Si hay pérdida de sustancia en los flexores con indemnidad de, por lo menos, A2 y A4, utilizo el FDS como injerto para la reconstrucción en agudo del FDP. Si el sistema de poleas está muy dañado, coloco una varilla reconstruyendo, al menos, A2 y A4, y confecciono un asa entre los cabos proximales de ambos flexores tal cual lo describió Paneva-Holevich (Figura 2).$^{29}$ Es recomendable tener varillas en el quirófano si vamos a tratar heridas complejas. Rara vez hago una reconstrucción de poleas junto con la tenorrafia; en estos casos, suele haber restos de polea para suturar un injerto a modo de puente; si es posible, utilizo una de las bandeletas del FDS conservando su inserción distal para reconstruir A4 y palmar menor o FDS como injertos para A2 (Figura 8). Si la herida se acompaña de fracturas de falanges, lo ideal es que la osteosíntesis sea suficientemente estable para mover el dígito y que no interfiera con el deslizamiento del tendón.

Como se describió en párrafos anteriores, durante los últimos 30 años, se han producido cambios significativos en la forma de tratar los flexores; cambios que actualmente intento aplicar (Tabla 2).

Si la herida es simple, prefiero operar con anestesia local con epinefrina y sin manguito, tal como lo describe Lalonde. Si entiendo que el procedimiento será sencillo, utilizo anestesia local sin epinefrina y manguito hemostático durante $30 \mathrm{~min}$, lo que me da tiempo para suturar el tendón. Luego, suelto el manguito para probar el DEFT.

En general, se trata de heridas transversales u oblicuas por corte; me gusta prolongarlas con incisiones tipo Bruner o en bayoneta. Es de buena práctica levantar los colgajos con tejido celular para no desvascularizarlos, si los paquetes están sanos quedan incluidos en ellos y si hay alguno lesionado lo reparo, pero trato de disecarlo sin traumatizar la piel (Figura 9).

El sufrimiento o la necrosis de los colgajos de piel es, a mi juicio, la peor complicación en la reparación primaria de los flexores, ya que, en los casos más leves, nos obliga a suspender cualquier protocolo de rehabilitación con la consiguiente formación de adherencias y, en los casos graves, puede resultar en necrosis del tendón reparado que requiera colgajos de cobertura y reconstrucción tendinosa secundaria en uno o dos tiempos. 


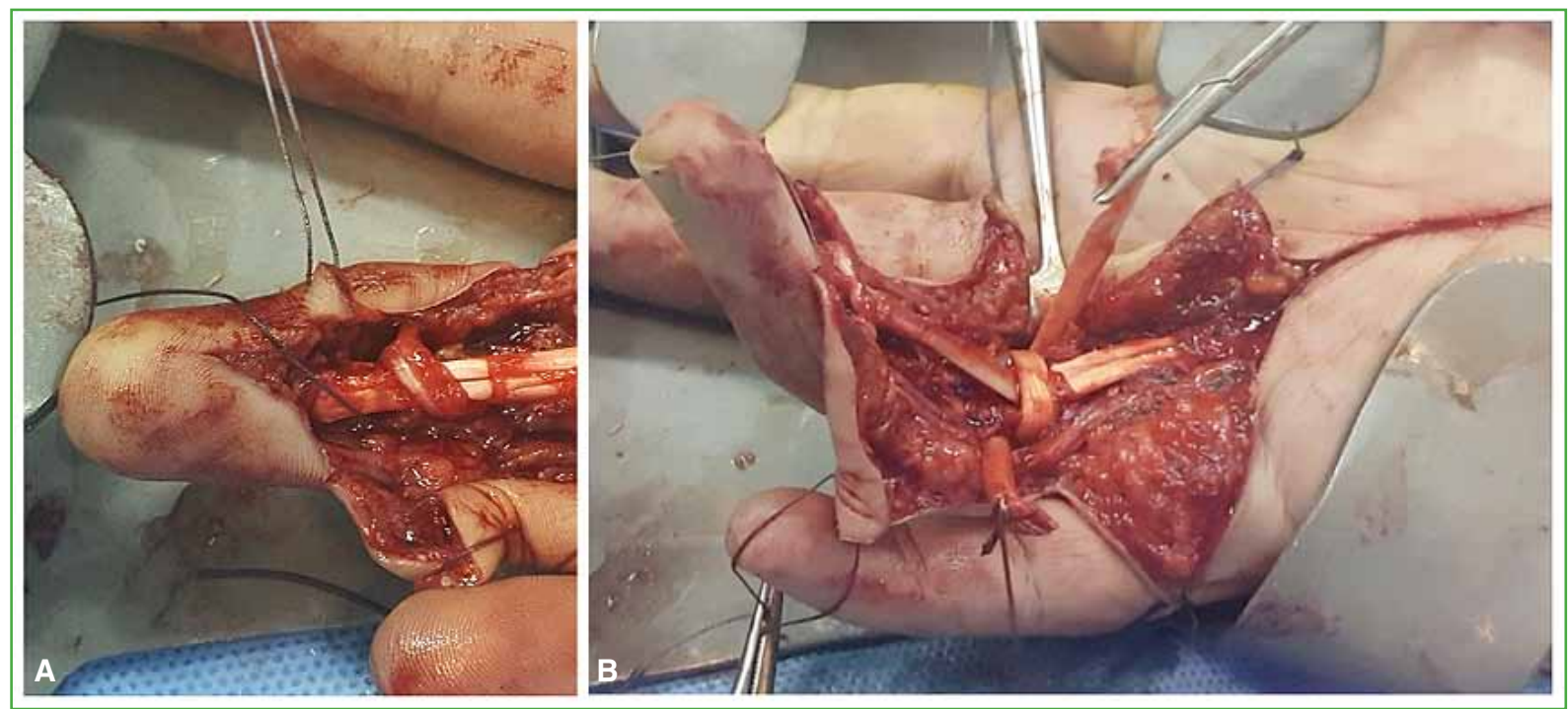

Figura 8. Reconstrucción de poleas. A. Reconstrucción de A4 con bandeleta del flexor superficial. B. Reconstrucción de A2 con flexor superficial.

Tabla 2. Cambios significativos de los últimos 30 años

\begin{tabular}{|c|c|c|}
\hline & Antes & Ahora \\
\hline Punto central & 2 hebras & 4 o más hebras \\
\hline Tratamiento de la vaina & Vaina cerrada & Vaina abierta \\
\hline Poleas A2 y A4 & A2 y A4 enteras & $\begin{array}{l}\text { A2 se puede abrir hasta } 2 / 3 \\
\text { A } 4 \text { completa }\end{array}$ \\
\hline $\begin{array}{l}\text { Flexor superficial de los } \\
\text { dedos }\end{array}$ & Se sutura siempre & Se puede resecar para evitar fricción \\
\hline Tipo de anestesia & Plexual con manguito & WALANT prueba de flexo-extensión activa intraoperatoria \\
\hline Férula posoperatoria & Férula con muñeca flexa & $\begin{array}{l}\text { Férula con muñeca neutra, } \\
\text { casos muy seleccionados sin férula }\end{array}$ \\
\hline Protocolo de rehabilitación & $\begin{array}{l}\text { Solo flexión pasiva a partir } \\
\text { de las } 48 \mathrm{~h}\end{array}$ & Flexión activa controlada a partir del $5^{\circ}$. día \\
\hline
\end{tabular}

Una vez expuesta la vaina hay que observar qué grado de lesión tiene. En las heridas simples, por lo general, las poleas están enteras. Suelo abrir la vaina a nivel del corte y de las poleas cruciformes cercanas.

El cabo proximal del FDP se encuentra cerca de la lesión si la víncula está sana (Figura 10); en cambio, suele estar retraído en la palma si la víncula se rompió. En ocasiones, si el paciente estaba haciendo fuerza de puño en el momento del accidente puede estar enrulado hacia proximal, pero siempre amarrado al lumbrical (Figura 11), entonces, prolongo la incisión de piel hasta la palma. Allí busco el(os) cabo(s) proximal(es) y los enhebro a través de las poleas utilizando un pasatendón o una simple cánula de silicona con un punto de nailon. El cabo distal del FDP llegará a la zona de sutura flexionando la articulación interfalángica distal (Figura 12). 

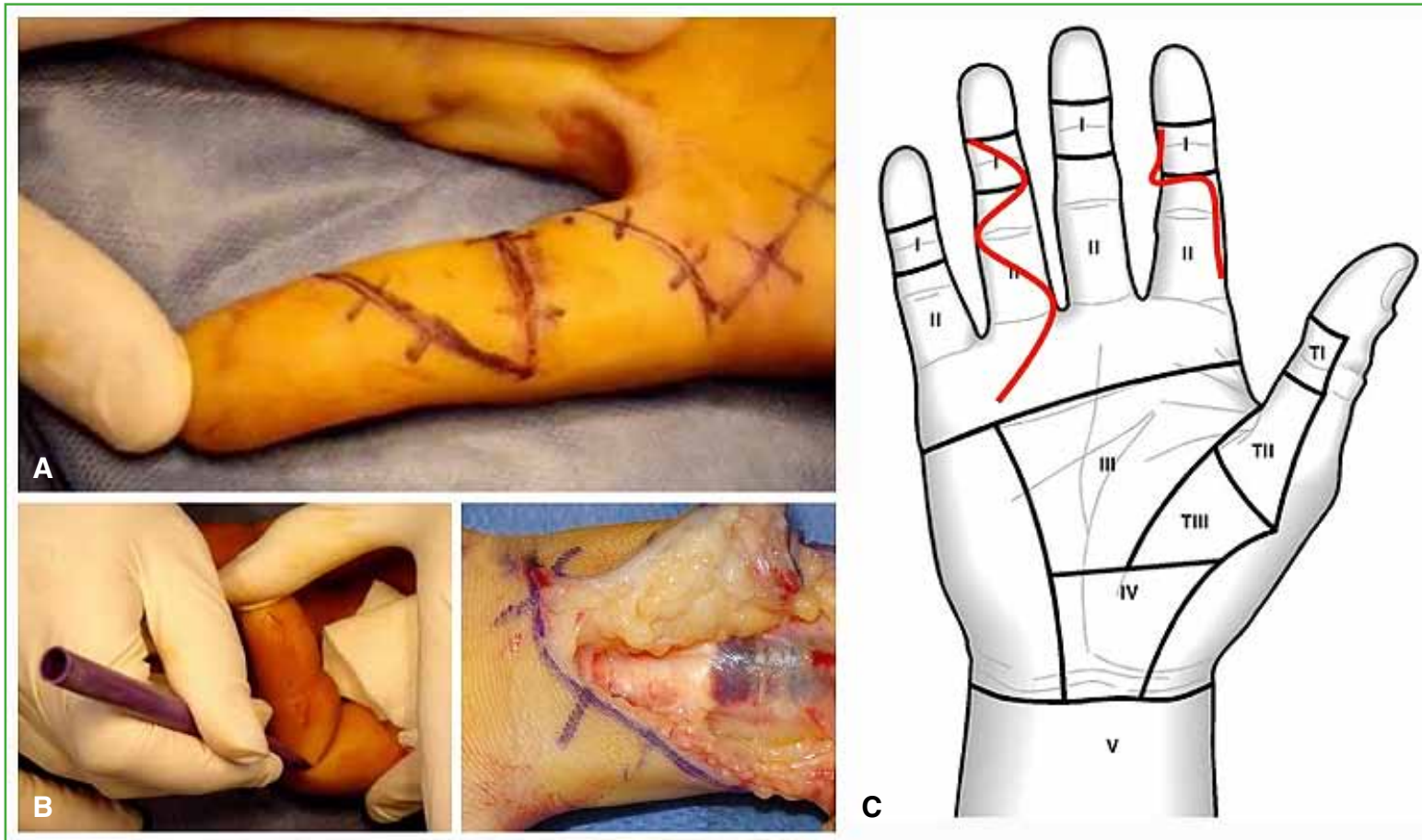

Figura 9. Incisiones cutáneas. A. Incisión tipo Bruner. B. Quiebre en el límite lateral del pliegue. C. Levantar colgajos con tejido celular subcutáneo para evitar desvitalizarlos.

Una vez enhebrados los cabos proximales se los puede sostener en su lugar usando una aguja intramuscular atravesando los tendones y fijándolos a la vaina (Figuras 10, 12 y 13). Si la lesión es a nivel de la articulación interfalángica proximal, hay que respetar la posición del quiasma de Camper y quizás para ello sea necesario abrir la porción más distal de A2 (se puede resecar o simplemente abrir). La lesión del FDS en zona de bandeletas la suturo con un punto en U de 3-0 en cada una (Figura 13). Si el FDS está lesionado en su porción entera, lo reparo de la misma forma que el FDP. Para el punto central utilizo nailon 3-0 con doble hilo, prefiero la configuración de Kessler modificada que dejará cuatro hebras de lado a lado con cuatro amarres tipo Pennington. Si hay vínculas sanas, procuro realizar el punto en la mitad volar del área circunferencial para respetar la nutrición, ya que ingresan por la zona dorsal del tendón. Si no puedo acceder al hilo doble, hago un punto central cruzado (4 hebras). Agrego un surget periférico con nailon 6-0 sutura continua (Figura 13). Hay que recordar que para poder indicar la flexión activa temprana la sutura deberá tolerar $40 \mathrm{~N}$ de carga durante la primera semana y esto implica que pasen, al menos, cuatro hebras de lado a lado con cuatro amarres trabados y un surget periférico. A continuación, realizo el DEFT y compruebo la falta de gapping y fricción (Figura 14). Si observo fricción, prefiero abrir más vaina o resecar una bandeleta del FDS, si fuera necesario, no dudo en resecarlo por completo. Si observo gapping, rehago la sutura.

Por el momento, no agrego sustancias para intentar manipular químicamente el proceso de reparación o las adherencias, ya que aún se están estudiando.

Cierro la piel con puntos separados bien cercanos de nailon 4-0.

Siempre utilicé el método de Kleinert para rehabilitar a mis pacientes (extensión activa, flexión pasiva con banda elástica y una polea en la palma). Desde hace cinco años, trato de comprobar la resistencia de mi reparación con el DEFT y luego del quinto día posoperatorio, comienzo con la movilidad activa no resistida controlada. Si no puedo probar la flexo-extensión intraoperatoria y tengo dudas con respecto a la resistencia de la configuración elegida indico Kleinert desde el comienzo (Figura 6). 


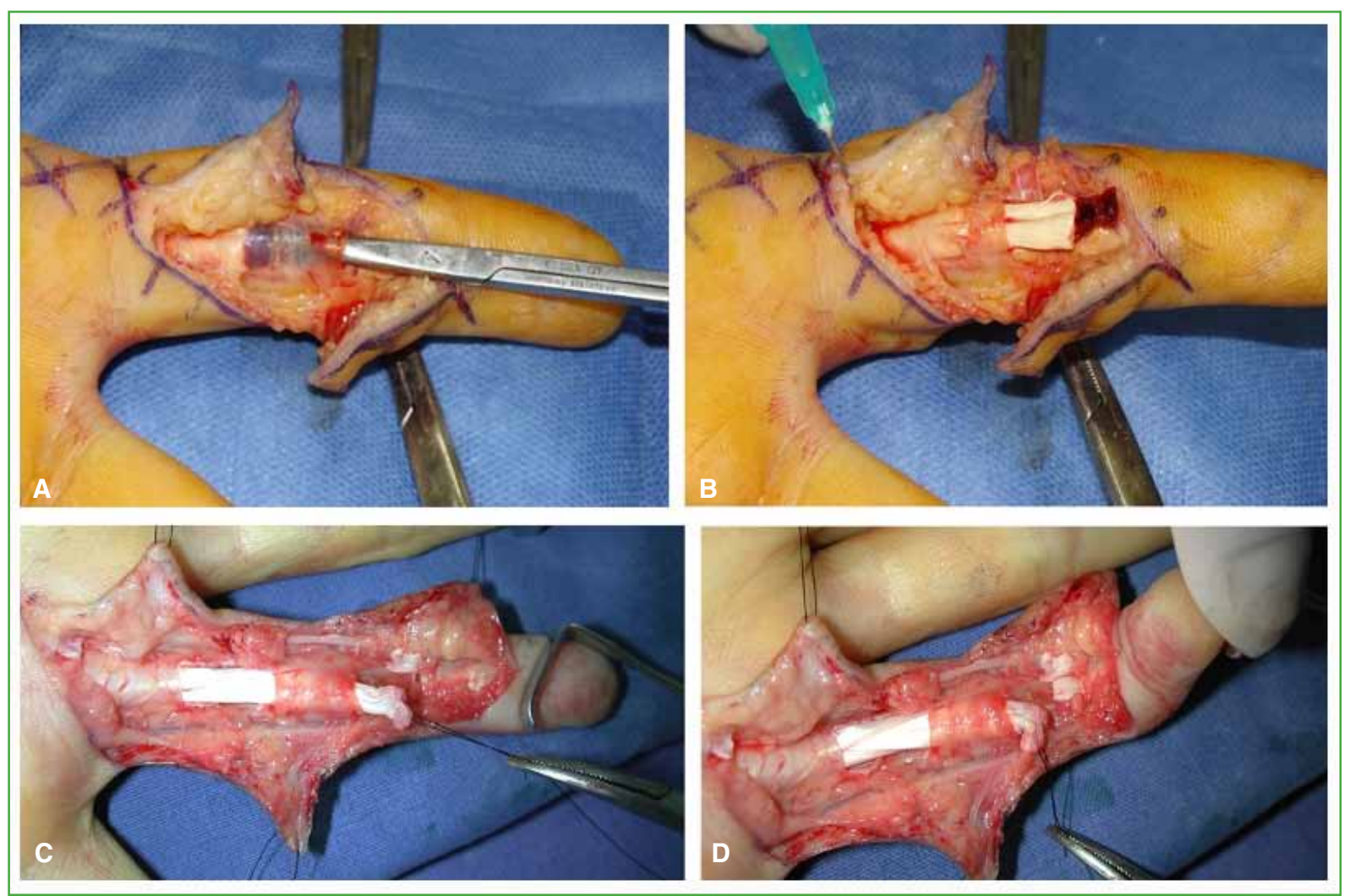

Figura 10. A. Si la víncula está sana, el cabo proximal se encuentra cerca. B. Cabo pescado y sostenido con aguja intramuscular que lo fija a la vaina. C y D. Acercamiento del cabo distal flexionando la articulación interfalángica distal.

\section{EL FUTURO}

La manipulación farmacológica del proceso de reparación está en etapa experimental. El objetivo es aumentar la capacidad intrínseca de reparación tendinosa y disminuir la formación de adherencias. Los elementos que pueden mejorar la reparación son: células indiferenciadas parecidas a las que se encuentran en el epitendón y los factores de crecimiento que promueven la proliferación celular y la producción de colágeno. Se está trabajando con suturas sembradas con células madre. ${ }^{30}$ También se está probando inyectar factores de crecimiento en los cabos tendinosos, como su vida útil es corta, se impregnan polímeros con factores de crecimiento para producir una liberación prolongada. ${ }^{31,32}$ Otro método es la terapia génica: se identifican los genes que producen factores de crecimiento, se los coloca en un vector viral (adenovirus), este conjunto denominado transgén se inyecta en los cabos tendinosos y se consigue una producción continuada de factores de crecimiento durante cuatro semanas. ${ }^{33}$

Las sustancias que, inyectadas en la zona, podrían disminuir las adherencias son: el 5-fluorouracilo, el ácido hialurónico o un ARN de interferencia que silencia factores que favorecen la fibrosis. La exposición de los tejidos al 5-fluorouracilo durante $5 \mathrm{~min}$ inhibe la proliferación de fibroblastos durante 36 días sin afectar la cicatrización intrínseca del tendón. ${ }^{34}$ Por otro lado, el ácido hialurónico favorecería el deslizamiento del tendón dentro de la vaina disminuyendo la fricción. ${ }^{35}$ También se está probando interponer tejidos que actúan como barrera para la cicatrización extrínseca, como la membrana amniótica. ${ }^{36}$

A pesar de que estas investigaciones aún no cuentan con el respaldo de pruebas en humanos, parece ser que el camino biológico lideraría los avances del futuro. 

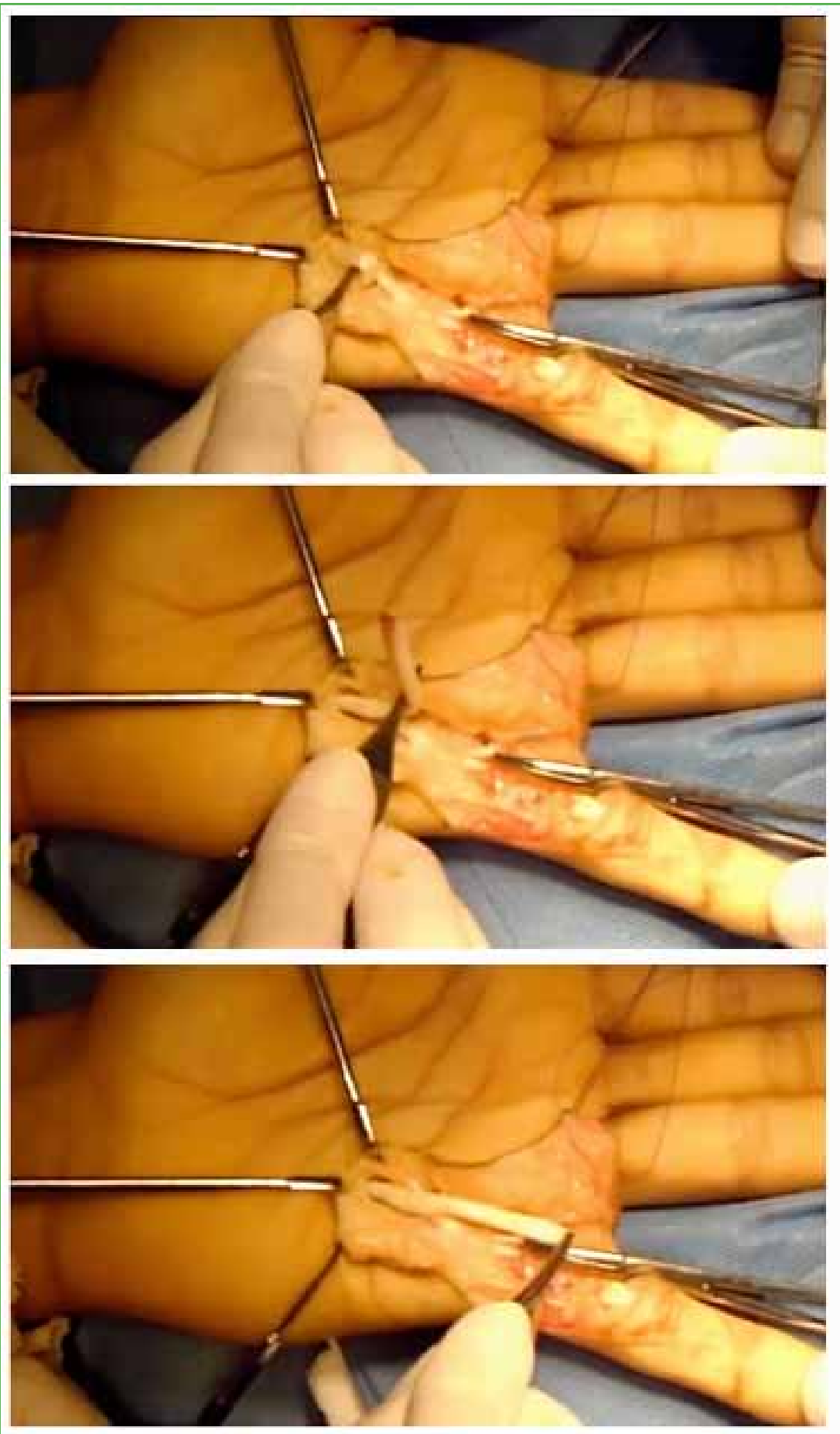

Figura 11. Cabo proximal en la palma, a veces, enrulado hacia proximal, pero siempre sostenido por el lumbrical. 


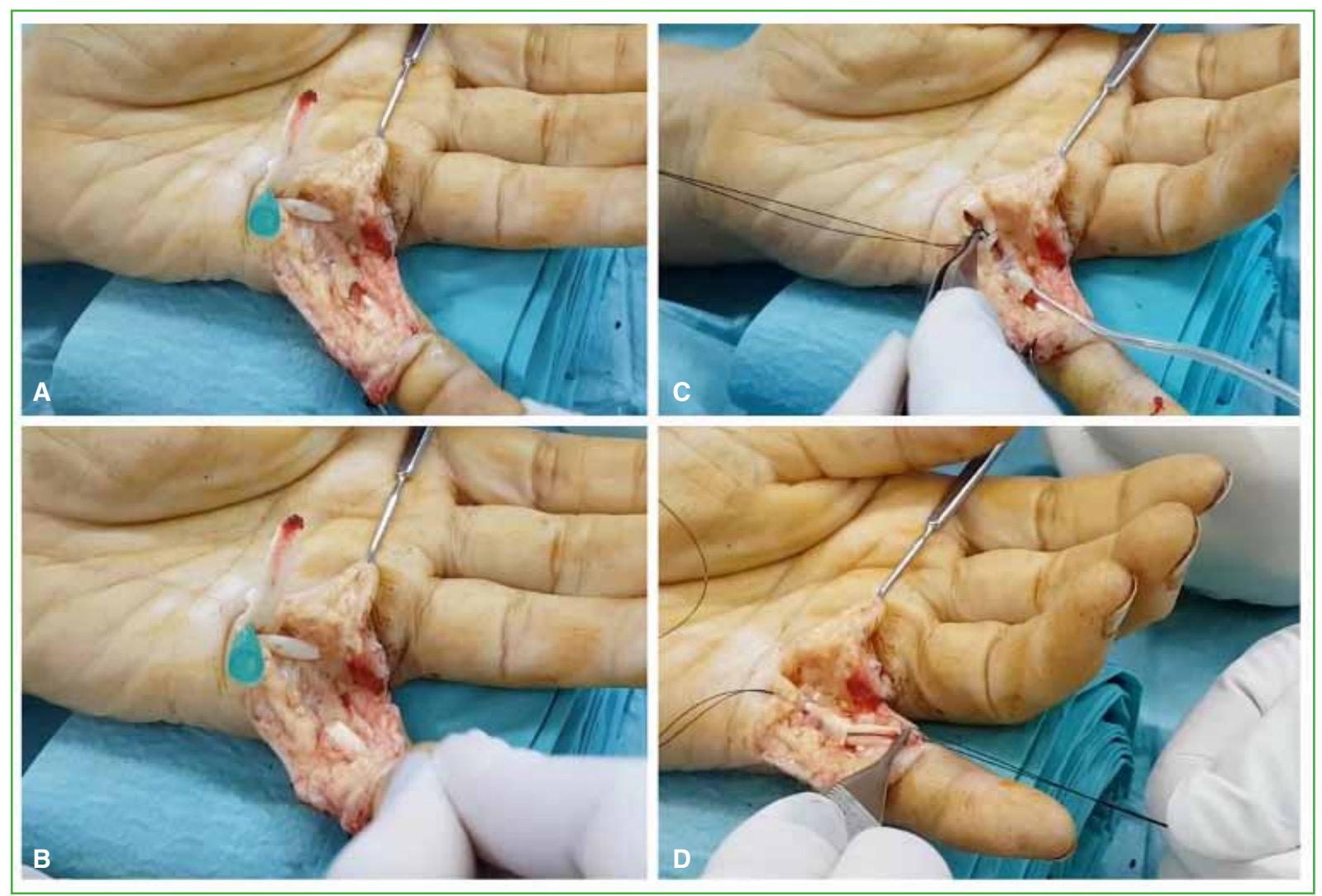

Figura 12. Enhebrado del cabo proximal. A. Se ubican cabos en palma. B. Flexionando las articulaciones distales aparece el cabo distal del flexor profundo. C y D. Enhebrado a través de A2 con una cánula y nailon.

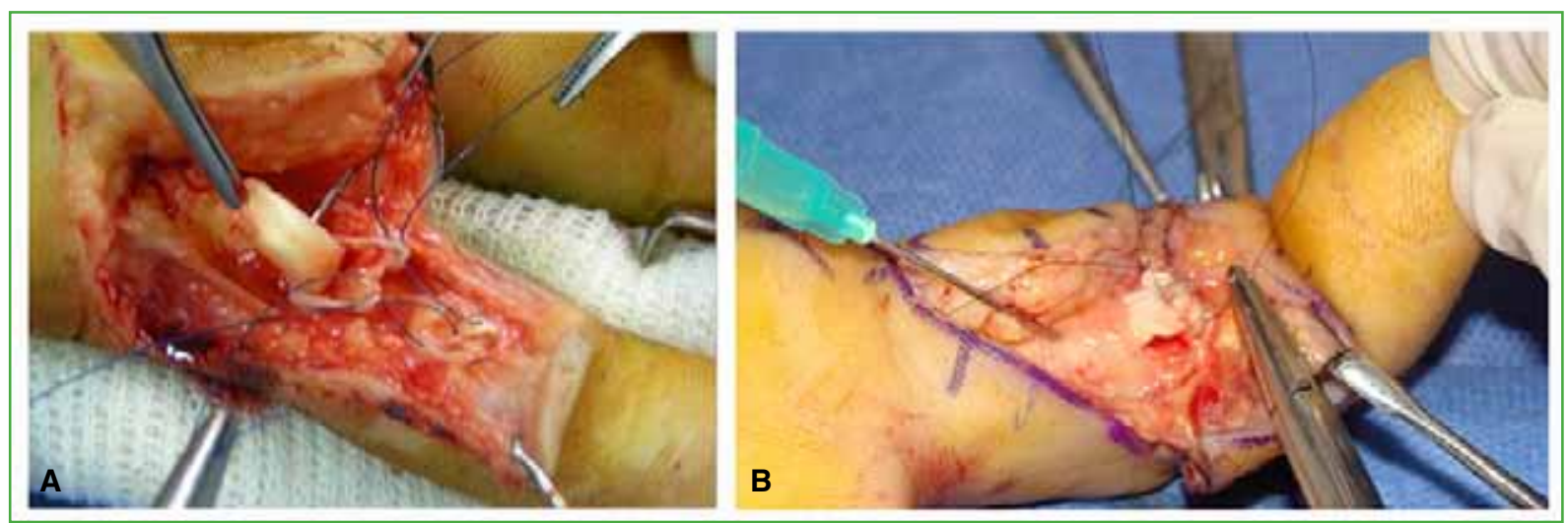

Figura 13. A. Sutura del flexor superficial con dos puntos en U de nailon 4-0 respetando el quiasma de Camper. B. Surget con nailon 6-0 luego del punto central. 

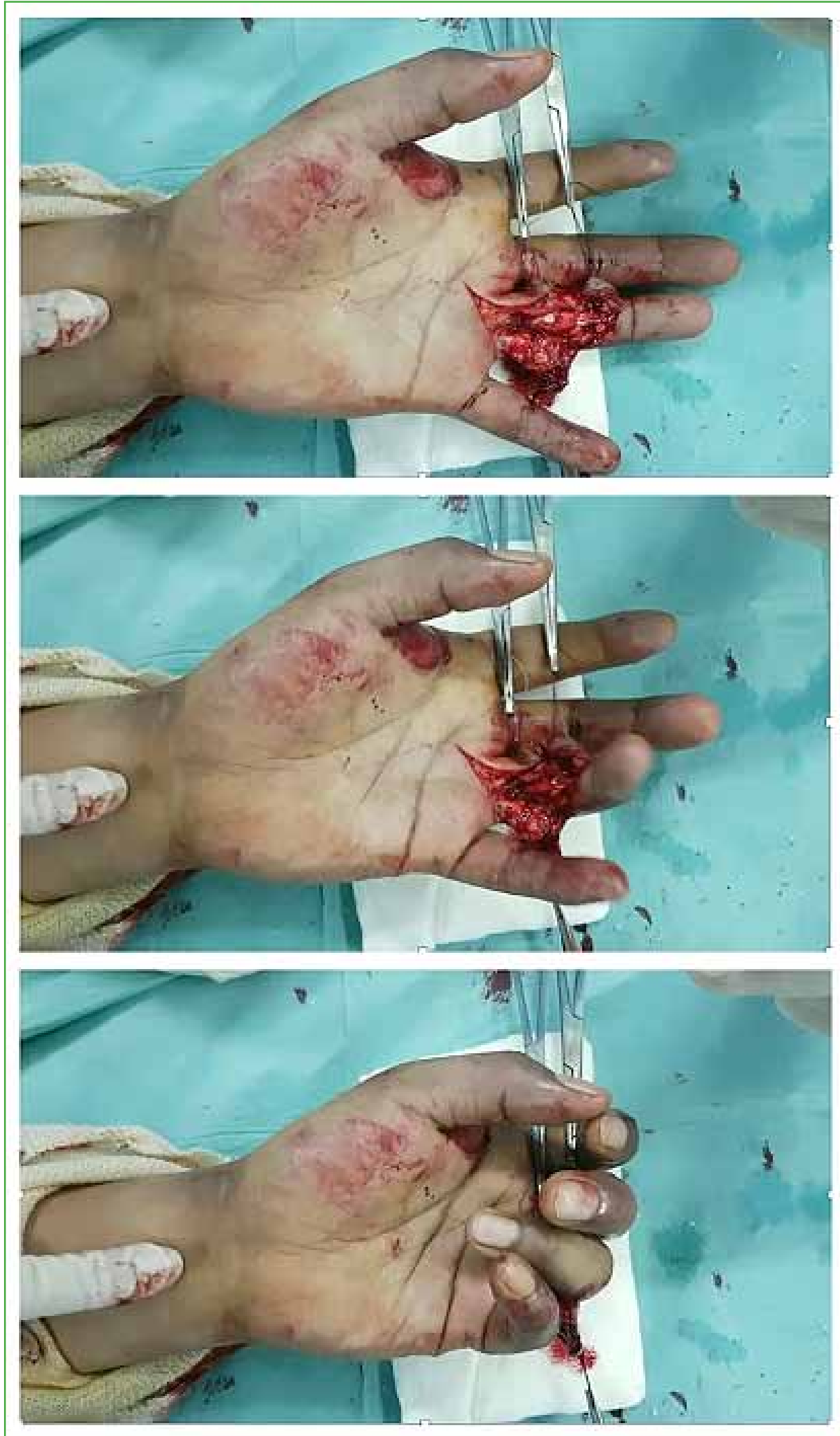

Figura 14. Prueba de flexo-extensión activa (digital extension-flexion test, DEFT) con el paciente despierto (WALANT: Wide Awake Local Anesthesia no Tourniquet). 
Conflicto de intereses: La autora no declara conflictos de intereses.

\section{BIBLIOGRAFÍA}

1. Clayton RA, Court-Brown CM. The epidemiology of musculoskeletal tendinous and ligamentous injuries. Injury 2008;39(12):1338-44. https://doi.org/10.1016/j.injury.2008.06.021

2. Kaplan EB, Hunter JM. Functional anatomy of the flexor tendon system: The muscles and tendon systems of the fingers. En: Hunter JM, Schneider LH, Mackin EJ (eds). Tendon and nerve surgery in the hand. A third decade. St. Louis, Mosby; 1997:240-52.

3. Fussey JM, Chin KF, Gogi N, Gella S, Deshmukh SC. An anatomic study of flexor tendon sheaths: a cadaveric study. J Hand Surg Eur 2009;34:762-5. https://doi.org/10.1177/1753193409344529

4. Doyle JR. Anatomy of the finger flexor tendon sheath and pulley system. J Hand Surg Am 1988;13:473-84. https://doi.org/10.1016/s0363-5023(88)80082-0

5. Strauch B, de Moura W. Digital flexor tendon sheath: an anatomic study. J Hand Surg Am 1985;10:785-9. https://doi.org/10.1016/s0363-5023(85)80152-0

6. Ochiai N, Matsui T, Miyaji N, Merklin RJ, Hunter JM. Vascular anatomy of flexor tendons. I. Vincular system and blood supply of the profundus tendon in the digital sheath. J Hand Surg Am 1979;4(4):321-30. https://doi.org/10.1016/s0363-5023(79)80068-4

7. Gelberman RH, Goldberg V, An KN, Banes A. Tendon. En: Woo SLY, Buckwalter JA (eds). Injury and repair of the musculoskeletal soft tissues. Park Ridge, IL: American Academy of Orthopaedic Surgeons; 1988:5-40.

8. Kryger GS, Chong AK, Costa M, Pham H, Bates S, Chang J. A comparison of tenocytes and mesenchymal stem cells for use in flexor tendon tissue engineering. J Hand Surg Am 2007;32(5):597-605. https://doi.org/10.1016/j.jhsa.2007.02.018

9. Manning CN, Havlioglu N, Knutsen E, Sakiyama-Elbert SE, Silva M, Thomopoulos S, et al. The early inflammatory response after flexor tendon healing: a gene expression and histological analysis. J Orthop Res 2014;32(5):645-52. https://doi.org/10.1002/jor.22575

10. Bunnell S. Repair of tendons in the fingers and description of two new instruments. Surg Gynecol Obstet 1918;26:103-10.

11. Verdan CE. Practical considerations for primary and secondary repair in flexor tendon injuries. Surg Clin North Am 1964;44:951-70. https://doi.org/10.1016/s0039-6109(16)37336-4

12. Kleinert HE, Kutz JE, Ashbell TS, Martinez E. Primary repair of lacerated flexor tendons in "no man's land". $J$ Bone Joint Surg Am 1967;49:577. https://doi.org/10.1201/b17524-8

13. Kessler I, Nissim F. Primary repair without immobilization of flexor tendon division within the digital sheath: an experimental and clinical study. Acta Orthop Scand 1969;40(5):587-601. https://doi.org/10.3109/17453676908989524

14. Strickland JW. Development of flexor tendon surgery: twenty-five years of progress. J Hand Surg Am 2000;25(2):214-35. https://doi.org/10.1053/jhsu.2000.jhsu25a0214

15. Tang JB, Amadio PC, Guimberteau JC, Chang J. Primary flexor tendon surgery. En: Tendon surgery of the hand. Philadelphia: Elsevier; 2012:79-258.

16. Tang JB, Xie RG, Cao Y, Ke ZS, Xu Y. A2 pulley incision or one slip of the superficialis improves flexor tendon repairs. Clin Orthop Relat Res 2007;456:121-7. https://doi.org/10.1097/01.blo.0000246564.96208.b0

17. Tang JB. Wide-awake primary flexor tendon repair, tenolysis, and tendon transfer. Clin Orthop Surg 2015;7(3):27581. https://doi.org/10.4055/cios.2015.7.3.275

18. Lalonde DH, Martin AL. Wide-awake flexor tendon repair and early tendon mobilization in zones 1 and 2 . Hand Clin 2013;29(2):207-13. https://doi.org/10.1016/j.hcl.2013.02.009

19. Miller B, Dodds SD, deMars A, Zagoreas N, Waitayawinyu T, Trumble T. Flexor tendon repairs: the impact of fiberwire on grasping and locking core sutures. J Hand Surg Am 2007;32(5):591-6. https://doi.org/10.1016/j.jhsa.2007.03.003

20. Wu YF, Cao Y, Zhou YL, Tang JB. Biomechanical comparisons of four-strand tendon repairs with double-stranded sutures: effects of different locks and suture geometry. J Hand Surg Eur 2011;36(1):34-9.

https://doi.org/10.1177/1753193410379554 
21. Su BW, Protopsaltis TS, Koff MF, Chang KP, Strauch RJ, Crow SA, et al. The biomechanical analysis of a tendon fixation device for flexor tendon repair. J Hand Surg Am 2005;30(2):237-45. https://doi.org/10.1016/j.jhsa.2004.07.020

22. Hirpara KM, Sullivan PJ, O'Sullivan ME. A new barbed device for repair of flexor tendons. J Bone Joint Surg Br 2010;92(8):1165-70. https://doi.org/10.1302/0301-620X.92B8.23029

23. Duran RJ, Houser RG, Coleman CR, Stover MG. Management of flexor tendon lacerations in zone 2 using controlled passive motion postoperatively. En: Hunter JM, Schneider LH, Mackin EJ (eds). Rehabilitation of the hand. St. Louis: Mosby; 1978:217-24.

24. Zhao CF, Amadio PC, Zobitz ME, Momose T, Couvreur P, An K. Effect of synergistic motion on flexor digitorum profundus tendon excursion. Clin Orthop Relat Res 2002;396:223-30. https://doi.org/10.1097/00003086-200203000-00033

25. Silfverskiöld KL, May EJ, Törnvall AH. Flexor digitorum profundus excursions during controlled motion after flexor tendon repair in excursions during controlled motion after flexor tendon repairs in zone II: aprospective clinical study. J Hand Surg Am 1992;17(1):122-31. https://doi.org/10.1016/0363-5023(92)90127-b

26. Strickland JW. Flexor tendon repair: Indiana method. Indiana Hand Center Newsletter 1993;1:1-12.

27. Groth GN. Pyramid of progressive force exercises to the injured flexor tendon. J Hand Ther 2004;17(1):31-42. https://doi.org/10.1197/j.jht.2003.10.005

28. Savage R. The influence of wrist position on the minimum force required for active movement of the interphalangeal joints. J Hand Surg 1988;13(3):262-8. https://doi.org/10.1016/0266-7681(88)90082-4

29. Paneva-Holevich E. Two-stage reconstruction of the flexor tendons. Int Orthop 1982;6(2):133-8. https://doi.org/10.1007/BF00268657

30. Yao J, Korotkova T, Riboh J, Chong A, Chang A, Smith R. Bioactive sutures for tendon repair: assessment of a method of delivering pluripotential embryonic cells. J Hand Surg Am 2008;33(9):1558-64. https://doi.org/10.1016/j.jhsa.2008.06.010

31. Chan BP, Fu S, Qin L, Rolf CG, Chan K. Effects of basic fibroblast growth factor (bFGF) on early stages of tendon healing: a rat patellar tendon model. Acta Orthop Scand 2000;71(5):513-8. https://doi.org/10.1080/000164700317381234

32. Thomopoulos S, Das R, Silva MJ, Sakiyama-Elbert S, Harwood FL, Zampiakis E, et al. Enhanced flexor tendon healing through controlled delivery of PDGF-BB. J Orthop Res 2009;27(9):1209-15. https://doi.org/10.1002/jor.20875

33. Kaplitt MG, Feigin A, Tang C, Fitzsimons HL, Mattis P, Lawlor PA, et al. Safety and tolerability of gene therapy with an adeno-associated virus (AAV) borne GAD gene for Parkinson's disease: an open label, phase I trial. Lancet 2007;369(9579):2097-105. https://doi.org/10.1016/S0140-6736(07)60982-9

34. Moran S, Ryan C, Orlando G, Pratt C, Michalko K. Effects of 5-fluorouracil on flexor tendon repair. J Hand Surg Am 2000;25:242-50. https://doi.org/10.1053/jhsu25a0242

35. Moro-oka T, Miura H, Mawatari T, Kawano T, Nakanishi Y, Higaki H, et al. Mixture of hyaluronic acid and phospholipid prevents adhesion formation on the injured flexor tendon in rabbits. J Orthop Res 2000;18(5):835-40. https://doi.org/10.1002/jor.1100180523

36. Liu C, Bai J, Yu K, Liu G, Tian S, Tian D. Biological amnion prevents flexor tendon adhesion in zone II: acontrolled, multicentre clinical trial. Biomed Res Int 2019;2019:2354325. https://doi.org/10.1155/2019/2354325 